Article

\title{
Mechanical Assessment of Glass Ionomer Cements Incorporated with Multi-Walled Carbon Nanotubes for Dental Applications
}

\author{
Manuela Spinola ${ }^{1}$, Amanda Maria Oliveira Dal Piva ${ }^{2, *} \mathbb{D}$, Patrícia Uchôas Barbosa ${ }^{1}$, Carlos Rocha Gomes Torres ${ }^{1}$ \\ and Eduardo Bresciani ${ }^{1}$ \\ 1 Department of Restorative Dentistry, Institute of Science and Technology, São Paulo State \\ University—UNESP, São José Dos Campos 12220-000, Brazil; spinola.manu@gmail.com (M.S.); \\ patriciauchoas@yahoo.com.br (P.U.B.); carlos.rg.torres@unesp.br (C.R.G.T.); \\ eduardo.bresciani@unesp.br (E.B.) \\ 2 Department of Dental Materials and Prosthodontics, Institute of Science and Technology, São Paulo State \\ University-UNESP, São José Dos Campos 12220-000, Brazil \\ * Correspondence: amodalpiva@gmail.com; Tel.: +55-3947-9000
}

Citation: Spinola, M.; Dal Piva, A.M.O.; Barbosa, P.U.; Torres, C.R.G.; Bresciani, E. Mechanical Assessment of Glass Ionomer Cements Incorporated with Multi-Walled Carbon Nanotubes for Dental Applications. Oral 2021, 1, 190-198. https://doi.org/10.3390/oral1030019

Academic Editor: Eugenio Pedullà

Received: 3 May 2021

Accepted: 5 July 2021

Published: 8 July 2021

Publisher's Note: MDPI stays neutral with regard to jurisdictional claims in published maps and institutional affiliations.

Copyright: (c) 2021 by the authors. Licensee MDPI, Basel, Switzerland. This article is an open access article distributed under the terms and conditions of the Creative Commons Attribution (CC BY) license (https:// creativecommons.org/licenses/by/ $4.0 /)$.

\begin{abstract}
Background: Nanoparticles such as multi-walled carbon nanotubes present resistance, resilience and biocompatibility with human tissues and could be incorporated into glass ionomer cement materials to improve their characteristics. Therefore, the aim of the present study was to evaluate the effect of multi-walled carbon nanotube (MWCNT) incorporation on different glass ionomer cements' compressive $(\sigma c)$ and diametral tensile strengths $(\sigma t)$. Methods: Eighty (80) specimens were divided into four groups $(\mathrm{N}=20 / \mathrm{gr})$ according to the glass ionomer cement type (conventional and high-viscosity) and the presence or absence of multi-walled carbon nanotubes. Samples were kept in water for $24 \mathrm{~h}$ prior to the tests. Data were analyzed using two-way ANOVA and Tukey's test $(p=0.05)$. Results: For both $\sigma c(p=0.1739)$ and $\sigma \mathrm{t}(p=0.2183)$, the glass ionomer cements' viscosity did not influence the results. The presence of MWCNTs decreased the mean compressive strength values $(p=0.0001)$ and increased the diametral tensile strength $(p=0.0059)$. For both conventional and high-viscosity glass ionomer cements, the compressive strength values were higher than the tensile strength data. Conclusions: Regardless of the cement viscosity, the multi-walled carbon nanotube incorporation reduced the compressive strength and increased the tensile strength values.
\end{abstract}

Keywords: glass ionomer cements; dental materials; compressive strength; tensile strength; carbon nanotubes

\section{Introduction}

The atraumatic restorative treatment (ART) technique is based on minimal intervention philosophy that removes decayed tissue using hand tools followed by cavity restoration with glass ionomer cement (GIC) [1]. Normally, this technique is performed in situations where conventional rotary instruments cannot be used, e.g., a lack of electricity, or in special situations, such as children or special patients, among them, those who suffer from anxiety [2,3]. Another advantage to using the ART technique associated with GIC is the possibility of not generating aerosols. This topic has become very important because of the COVID-19 pandemic, since the formation of aerosols causes a large dispersion of microorganisms which increases the possibility of contamination. The use of atraumatic procedures is important to improve patients' quality of life, provide the most friendly dental treatment and reduce further complications and psychological issues $[4,5]$.

GICs are suitable materials because of their properties such as biocompatibility, insulating effect in the oral temperatures, antibacterial capacity, fluoride release and the 
possibility of manual manipulation [6,7]. On the other hand, although GICs are the material of choice for the ART technique, this material presents a poor mechanical property for areas of large masticatory forces when compared to composite resin or amalgam [8]. This is still considered the main point of failure of this technique, which makes high-viscosity GIC more promising in comparison with low-viscosity GIC [6]. Regardless of the infected carious dentin layers [9], the ART technique with GIC could provide an adequate and accessible treatment.

To improve GICs' mechanical properties, the addition of different materials has been considered, such as metal, hydroxyapatite or even natural products such as propolis [10-12]. Currently, an approach involving the addition of carbon nanotubes in restorative materials has been reported due to its extraordinary mechanical, electrical and thermal properties and its ability to provide structural reinforcement to dental materials $[13,14]$. Besides presenting good mechanical properties, the incorporation of nanotubes presents important biological characteristics regarding the adhesion to odontoblasts and fibroblasts and the induction of apatite precipitation [15]. Therefore, previous investigations have evaluated the applications of carbon nanotubes in dentistry, such as: hydroxyapatite coatings, bone engineering, dental composites, polymethyl methacrylate, dental prostheses and cements [16].

The literature reports that adding fluorinated graphene to traditional GICs could improve the mechanical and tribological properties of the composites and their antibacterial properties [17]. However, the color stability of modified GIC could not be adequate for use in anterior esthetic restorations [18]. The influence of different GIC viscosities associated with multi-walled carbon nanotubes (MWCNTs) on different mechanical properties has not been investigated yet. Thus, the aim of the present study was to evaluate the compressive and tensile strengths of different GICs after incorporating, or not, MWCNT. The null hypothesis was that there is no mechanical difference between the different GICs after MWCNT incorporation.

\section{Materials and Methods}

Four groups (Table 1) were manufactured according to the GIC (conventional (Aqua Ionofil Plus, Voco, Cuxhaven, Germany) and low-viscosity (Argion Molar, Voco, Cuxhaven, Germany)) and carbon nanotube incorporation (present or not). The nanotubes were manufactured in the Nanomaterials Laboratory of the Physics Department in the University of Minas Gerais [19]. The carbon nanotubes had an average length of $200 \mathrm{~nm}$ and an average outer diameter of $25 \mathrm{~nm}$ and were functionalized through oxidation in nitric/sulfuric acid [19]. For both tested materials, the powder/liquid ratio followed the manufacturer's recommendation.

Table 1. Materials ${ }^{1}$ investigated in this study.

\begin{tabular}{|c|c|c|c|}
\hline Material & Type & Average Particle Size $(\mu \mathrm{m})$ & Composition \\
\hline $\begin{array}{l}\text { Aqua Ionofil Plus, Voco, } \\
\text { Cuxhaven, Germany }\end{array}$ & $\begin{array}{l}\text { Conventional glass ionomer } \\
\text { cement restorative }\end{array}$ & $8 \mu \mathrm{m}$ & $\begin{array}{l}\text { Water, pure polyacrylic acid, } \\
\text { tartaric acid, } \\
\text { aluminofluorosilicate glass } \\
\text { and pigments }\end{array}$ \\
\hline $\begin{array}{l}\text { Ionofil Molar, Voco, } \\
\text { Cuxhaven, Germany }\end{array}$ & $\begin{array}{l}\text { low-viscosity glass ionomer } \\
\text { cement restorative }\end{array}$ & $5 \mu \mathrm{m}$ & $\begin{array}{l}\text { Water, pure polyacrylic acid, } \\
\text { tartaric acid, } \\
\text { aluminofluorosilicate glass } \\
\text { and pigments }\end{array}$ \\
\hline
\end{tabular}

${ }^{1}$ Glass ionomer cements used in the present study.

For this study (Figure 1), eighty (80) specimens were prepared with precision scales for measuring the amount of powder and automatic pipettes for liquid according to the manufacturer's instructions, followed by mixing using an appropriate block and flexible plastic spatula. GIC was poured into metal matrix mold with the aid of Centrix tips and pressed with polyester matrix and glass slide on the specimen, promoting a straight and smooth surface. The concentration of nanotubes incorporated into the GIC in the experi- 
mental group was $1 \%$ of the GIC mass powder, manually incorporated during the powder measurement and prior to the manipulation. The concentration was determined after a pilot study, which tested $1 \%, 5 \%, 10 \%$ and $15 \%$. The proper GIC manual manipulation by dentists could only be performed with $1 \%$ concentration, since higher concentrations resulted in a rubber material.
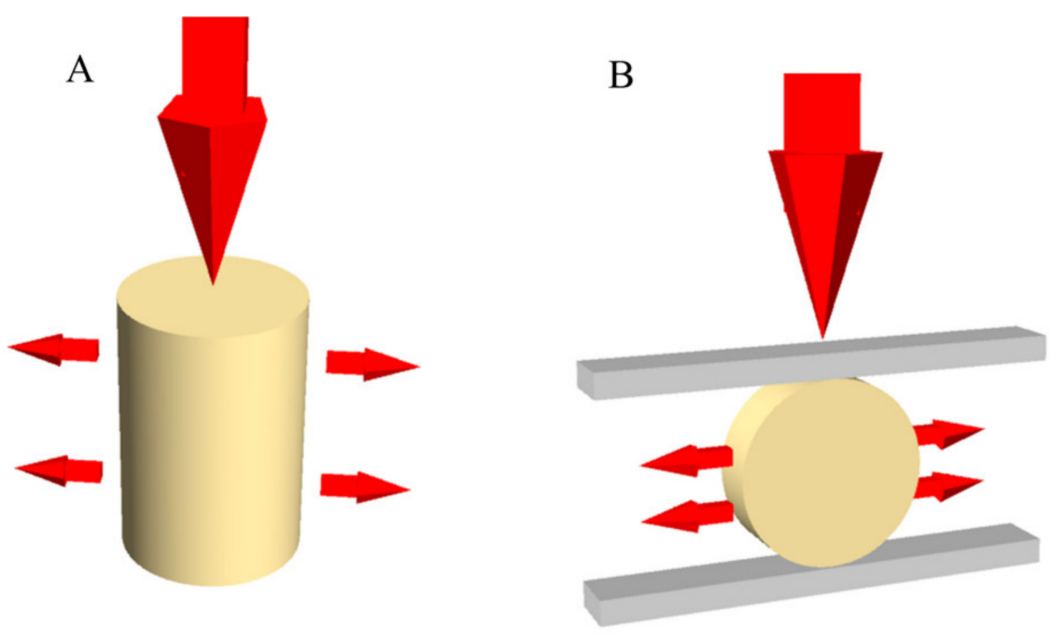

Figure 1. Schematic illustration of: (A) compressive strength test; and (B) diametral tensile strength test.

After the initial reaction, the specimens were removed from the matrix, and the surfaces were protected with petroleum jelly. They were stored for $24 \mathrm{~h}$ in deionized water. After this, specimens were subjected to compression and diametrical tensile tests.

For the compressive strength test, specimens $6 \mathrm{~mm}$ in height and $4 \mathrm{~mm}$ in diameter $(n=10$ per group; $N=40)$ were prepared using metal molds, following ISO 9917$1 / 2007$ [17]. A universal testing machine was employed to test the specimens using $0.5 \mathrm{~mm} / \mathrm{s}$ as the rate of loading. The compressive strength of samples was calculated with the following formula:

$$
\sigma_{\mathrm{c}}=\frac{\mathrm{F}}{\pi \mathrm{r}^{2}}
$$

where $\mathrm{F}=$ load to fracture, $\mathrm{r}=$ the radius of the specimen cylinder and $\pi=$ (constant) 3.14. Values of $\sigma \mathrm{c}\left(\mathrm{kgf} / \mathrm{cm}^{2}\right)$ were converted into MPa.

For the diametral tensile test, specimens were prepared ( $\mathrm{n}=10$ per group; $\mathrm{N}=40$ ) with dimensions of $2 \mathrm{~mm}$ in height and $4 \mathrm{~mm}$ in diameter in metal molds, according to ISO 9917-1/2007 [17]. A universal testing machine was employed to test samples using $0.5 \mathrm{~mm} / \mathrm{s}$ as the rate of loading. The diametral tensile strengths of samples were calculated with the following formula:

$$
\sigma_{\mathrm{t}}=\frac{2 \mathrm{~F}}{\pi \mathrm{dh}}
$$

where $\mathrm{F}=$ load applied, $\mathrm{d}=$ diameter of the cylinder, $\mathrm{h}=$ height of the cylinder and $\pi=$ (constant) 3.14. Values of $\sigma \mathrm{t}\left(\mathrm{kgf} / \mathrm{cm}^{2}\right)$ were converted into MPa.

After the compressive test, all specimens from each group were selected and inspected; however, a representative randomly selected specimen was captured $(70 \times, 2000 \times$ and $5000 \times$ magnification) using scanning electron microscopy (SEM; Inspect S50, FEI, Brno, Moravia, Czech Republic). The specimens were sputter coated with gold for $180 \mathrm{~s}$ at $40 \mathrm{~mA}$, creating a $30 \mathrm{~nm}$-thick coating layer, and then examined under different standard SEM magnifications operated at $20 \mathrm{kV}$ using secondary electron detection.

The data were tested for a normal distribution using the Shapiro-Wilk test. Since the data were normally distributed, two-way ANOVA and the Tukey test were used for both tested variables. The dependent factor was the values obtained in each test, and the independent factors were the tested materials (conventional or high-viscosity GIC), and 
the presence or absence of nanoparticles (MWCNT). The statistical analysis was performed considering a $95 \%$ confidence interval $(p=0.05)$.

\section{Results}

For both compressive $(p=0.1739)$ and tensile $(p=0.2183)$ strengths, the GIC viscosity did not influence the results. The presence of MWCNTs decreased the mean compressive strength values $(p=0.0001)$ and increased the diametral tensile strength $(p=0.0059)$.

Table 2 shows the mean values (MPa) and standard deviations obtained for the compressive strength and the diametral tensile strength for the evaluated conditions.

Table 2. Mean values (MPa) and standard deviations obtained for the compressive strength test and the diametral tensile strength test for the evaluated conditions.

\begin{tabular}{cccc}
\hline GIC & $\begin{array}{c}\text { Incorporated } \\
\text { MWCNTs }\end{array}$ & $\begin{array}{l}\text { Compressive } \\
\text { Strength }(\sigma \mathrm{c})\end{array}$ & Tensile Strength $(\boldsymbol{\sigma t})$ \\
\hline Conventional & no & $102.8 \pm 11.9^{*}$ & $15.20 \pm 2.2^{* * *}$ \\
Low-viscosity & yes & $86.9 \pm 14.6^{* *}$ & $21.20 \pm 5.5^{* * * *}$ \\
& no & $101.9 \pm 11.5^{*}$ & $19.03 \pm 2.8^{* * *}$ \\
& yes & $77.0 \pm 11.0^{* *}$ & $20.60 \pm 4.8^{* * * *}$ \\
\hline
\end{tabular}

Note: Values calculated in average. Similar quantity of superscript ${ }^{*}$ represents statistically similar groups.

For the microscopy analysis (Figure 2), it was possible to observe a similar surface pattern between the groups with similar viscosity. The presence of voids is less visible in the group with high-viscosity glass ionomer cement and absence of MWCNTs. In addition, at higher magnification $(5000 \times)$, it was possible to observe the presence of small cracks between the particles in the groups with MWCNTs; therefore, the structure between the groups was very similar.
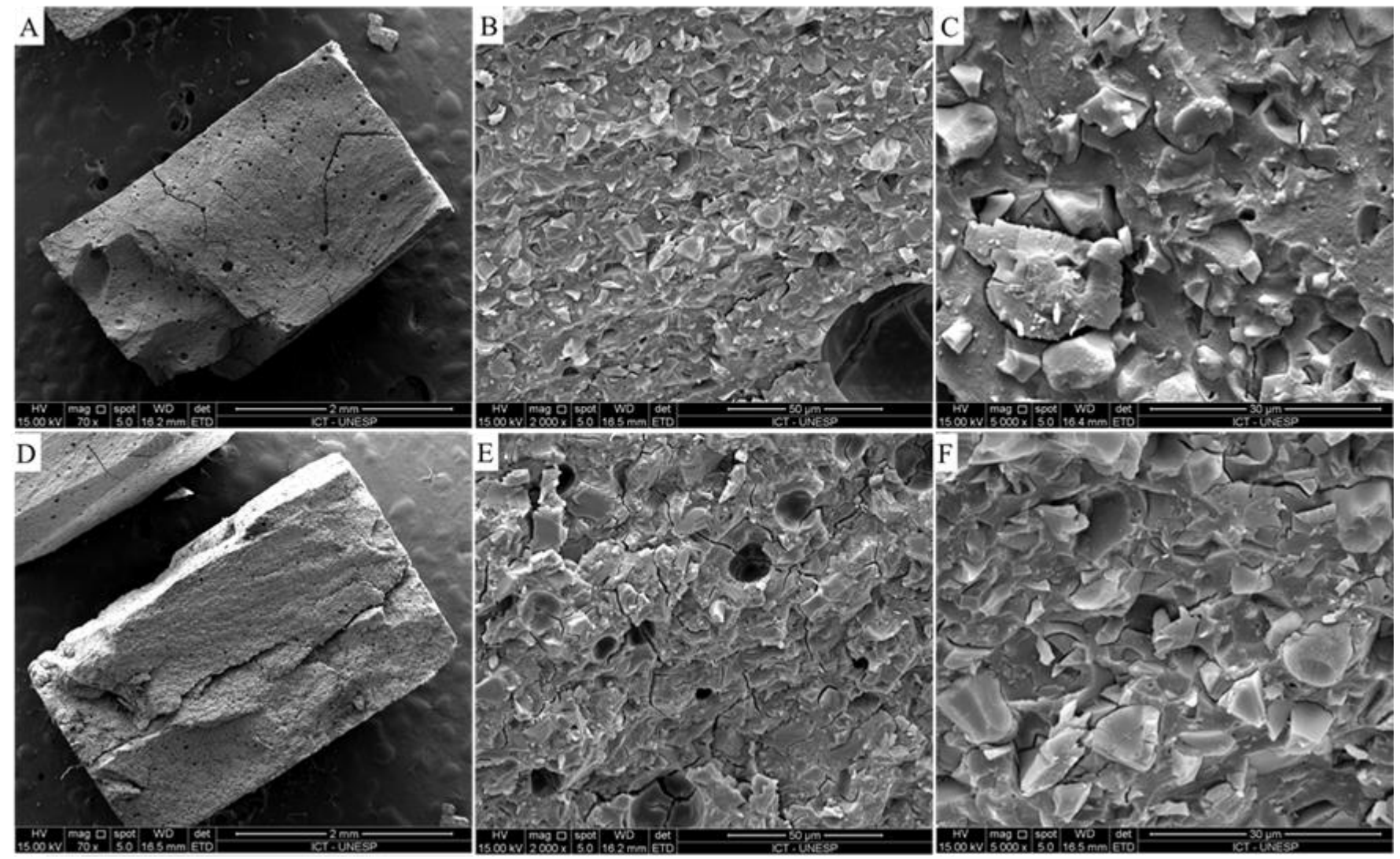

Figure 2. Cont. 

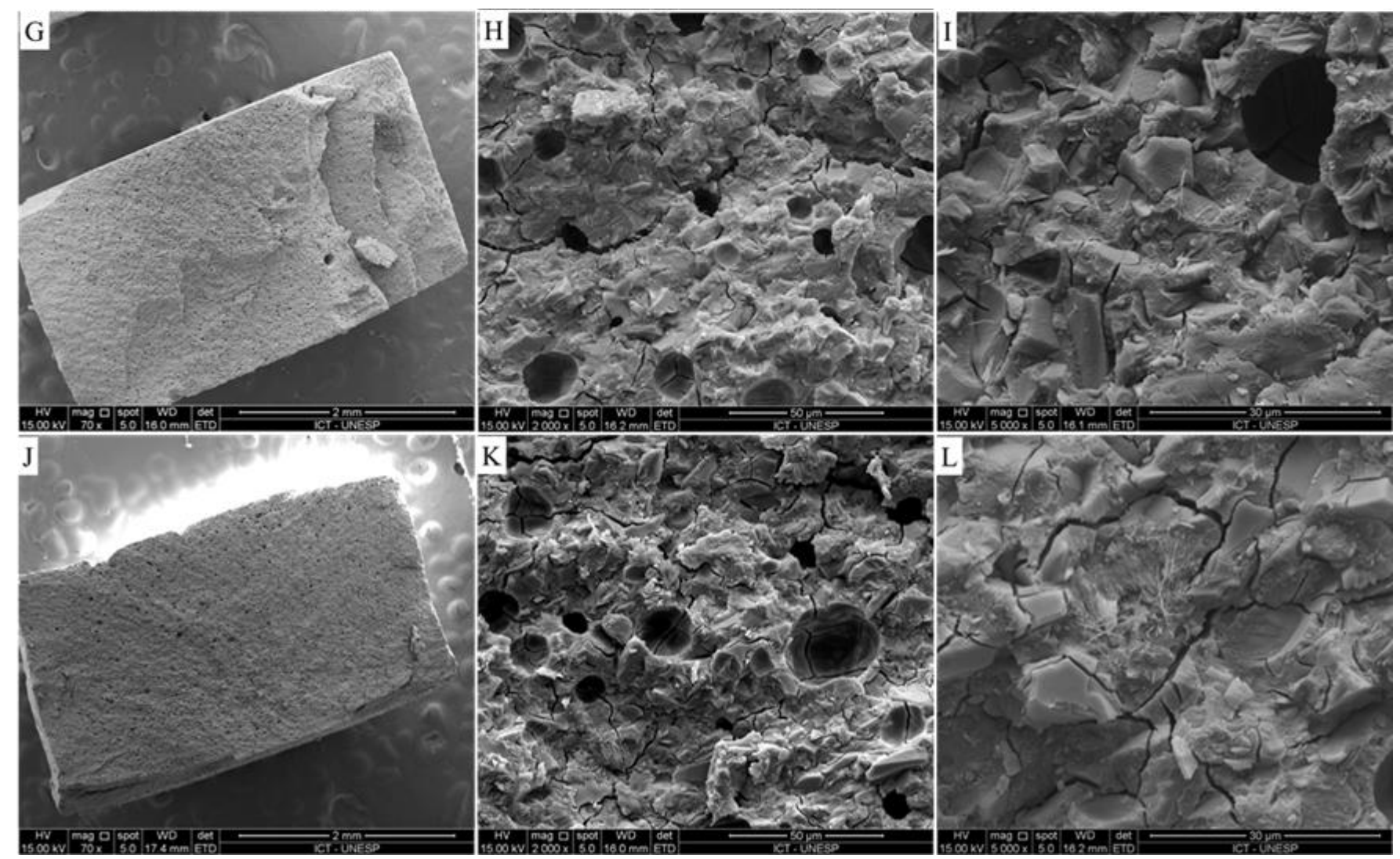

Figure 2. Scanning electron microscopy (SEM) of different specimens after the compressive strength test. (A-C) Highviscosity glass ionomer cement without MWCNT incorporation at 70, 1000 and 5000 $\times$ magnification; (D-F) high-viscosity glass ionomer cement with MWCNT incorporation at 70, 1000 and 5000× magnification; (G-I) conventional glass ionomer cement without MWCNT incorporation at 70, 1000 and 5000 $\times$ magnification; and (J-L) conventional glass ionomer cement with MWCNT incorporation at 70,1000 and 5000× magnification. Yellow arrows indicate the presence of small cracks between the GIC particles.

\section{Discussion}

The present study aimed to evaluate the effect of incorporating multi-walled carbon nanotubes (MWCNTs) into GICs with different viscosities through the evaluation of the compressive and tensile strengths. The results show that the mechanical properties were affected by the MWCNT incorporation, thus rejecting the null hypothesis.

Initially, GICs were modified by metal particles and resin components [10,20]. After that, GICs with higher viscosity were introduced, showing improved characteristics, but still presenting their resistance to the chewing forces as a principal disadvantage in comparison with composite materials. In the present study, MWCNT incorporation in conventional and high-viscosity GICs was tested. It was expected that the addition of nanoparticles could improve the mechanical properties of both tested materials, based on previous reports that found a reinforcement effect for restorative materials after MWCNT incorporation [16-18]. However, the findings of the present study showed that the MWCNT incorporation had a negative effect on the compressive strength of both glass ionomer cement materials.

From both evaluated properties, the compressive strength could be directly associated with the resistance against the masticatory forces, and therefore it allows for estimation of cements' clinical performance [21,22]. For a limited clinical extrapolation, the compressive strength could be associated with the patient's bite force. In this sense, a reduced compressive strength due to the MWCNT incorporation can reduce the restoration longevity, increasing the restorative material failure susceptibility. According to ISO 9917-1:2007 for water-based dental cements, the compressive strength of dental cements should be 
higher than $70 \mathrm{MPa}$ [23]. Therefore, all tested conditions showed superior strength to that recommended by the ISO. The presented results do not allow the indication of MWCNT incorporation in GIC regardless of the material viscosity. The specimens were stored prior to the mechanical testing $(24 \mathrm{~h}$ protocol) to ensure that the test was performed with the materials' final strength.

The tensile strength data are important because areas in the restoration with a high stress concentration could induce clinical failures due to crack propagation [24]. For a limited clinical extrapolation, the tensile strength could be associated with the aging process due the low-magnitude cyclic loadings. It is important to note that regardless of the MWCNT incorporation, the tensile strengths of both GICs were approximately five times lower than the compressive strength, explaining, for example, how a supposed harmless chewing load can lead to a tensile failure to occur. Although this mechanical behavior is more evident in more brittle materials such as dental ceramics [25] than in GICs, these cements are not completely viscoelastic [26-28], and the tensile strength is an important property widely investigated for this material [22,23]. The positive effect of MWCNT incorporation on the tensile strength occurred regardless of the GIC viscosity. However, with an inversely proportional result for the compressive strength, the clinical indication becomes extremely restrictive, and this positive effect seems not to be enough to indicate MWCNT incorporation as a reinforcement.

Although several studies in the literature attempted to improve GICs' properties with a major focus on their clinical use, the results are still conflicting. A previous report [24] showed that glass fibers, for example, when added to GICs, caused the fracture toughness to increase by $280 \%$ and the flexural strength by more than $170 \%$. This fact may be related to the degradation of the material, especially under masticatory loads after its insertion into the cavity, and should be associated with the chemical union of these particles.

MWCNTs promote a better wettability of the particles and can interact with the environment in which they are incorporated [29]. However, in this study, MWCNT incorporations did not improve GICs' compressive strengths. One possible explanation for the worst mechanical properties could be the possible agglomeration of nanoparticles instead of a homogeneous dispersion inside the cement matrix; however, the nanoparticles' dispersion was not evaluated. These agglomerations create regions of low resistance, leading to the observed results. In this study, the dispersion of the carbon nanotubes may not have been effective, probably caused during the manual mixture process. This observation reinforces the need for a proper protocol dispersion to homogeneously distribute the nanoparticles. For composite dental materials, the void content is an important property which affects the mechanical properties of dental composites, and thereby the overall performance of this restorative material under compressive load [30]. Based on this principle, it is possible to suggest that the nanoparticle agglomeration acts as a void content affecting the mechanical behavior of the GIC and could justify the presence of the small cracks observed in SEM (Figure 2). According to the literature [21], the mixture of particles at high speed promotes breakage of filler agglomerates, improving the interactions between the matrix and fillers. This method could be applied in further studies for GICs with MWCNTs.

To improve the GIC mechanical and adhesive properties, numerous filler components have been incorporated in this restorative material, including: silver amalgam particles, spherical silica, zirconia, glass fibers, hydroxyapatite and bioactive glass particles, as pre-reacted glass ionomer particles [29-33]. However, the literature reports that not only the type of filler is important but also the concentration used, and that they should be selected for the particular clinical use with a compromise between the elastic modulus, the compressive strength and the curing time [34,35]. The present study complements these statements suggesting the use of MWCNTs as a filler material; however, further studies are still necessary to determine the optimal concentration and nanoparticle dispersion.

One possible explanation to the different mechanical behaviors between compression and tensile stress can be the mechanism present in fiber-reinforced dental materials [31]. Therefore, anisotropy is the property of the restorative material to exhibit variations in 
physical properties along different axes (compression and tensile). This theory can be reinforced since the presence of carbon nanotubes in nanocomposites is reported as a material with anisotropic behavior for elasticity and electric properties $[33,36]$.

As one of the study's limitations, the present manuscript did not evaluate the aging process that occurs in the oral environment, e.g., thermal aging, mechanical cycling and $\mathrm{pH}$ variation that can affect the results presented here and the GIC mechanical behavior. The GIC color was also affected, which can compromise the use of the tested materials after MWCNT incorporation, and further studies are still necessary to improve it. Regarding the GIC indications, different cavity shapes and material combinations in the restoration can affect its performance and the mechanical response.

Another important limitation that needs to be reported is the difficult manipulation of both GICs after the MWCNT incorporation, presenting a rubber texture during in vitro specimen preparation, that could also be a negative factor for the ART technique [1], which needs to be precise and simple at the same time. However, further automatic mixing methods could be useful to allow the manipulation of GICs with higher MWCNT concentration incorporation. In addition, the absence of nanoparticle dispersion is another of the study's limitations that can be further investigated in order to complement the present results.

\section{Conclusions}

For conventional and high-viscosity glass ionomer cements, the compressive strength values were higher than the tensile strength data. Regardless of the cement viscosity, the multi-walled carbon nanotube incorporation reduced the compressive strength and increased the tensile strength data values.

Author Contributions: Conceptualization, M.S., A.M.O.D.P., P.U.B., C.R.G.T. and E.B.; methodology, M.S., A.M.O.D.P., P.U.B., C.R.G.T. and E.B.; software, M.S., C.R.G.T. and E.B.; validation, M.S., A.M.O.D.P., C.R.G.T. and E.B.; formal analysis, P.U.B. and E.B.; investigation, M.S., A.M.O.D.P., C.R.G.T. and E.B.; resources, M.S., A.M.O.D.P., P.U.B., C.R.G.T. and E.B.; data curation, M.S. and E.B.; writing — original draft preparation, M.S., A.M.O.D.P., P.U.B., C.R.G.T. and E.B.; writing—review and editing, M.S., A.M.O.D.P., P.U.B., C.R.G.T. and E.B.; visualization, M.S., A.M.O.D.P., P.U.B., C.R.G.T. and E.B.; supervision, C.R.G.T. and E.B.; project administration, C.R.G.T. and E.B.; funding acquisition, P.U.B. and E.B. All authors have read and agreed to the published version of the manuscript.

Funding: This research was funded by São Paulo Research Foundation (FAPESP) grant numbers 2012/22518-9 and 2012/19223-7.

Institutional Review Board Statement: Not applicable.

Informed Consent Statement: Not applicable.

Data Availability Statement: Data available on request.

Conflicts of Interest: The authors declare no conflict of interest.

\section{References}

1. Frencken, J.E. Atraumatic restorative treatment and minimal intervention dentistry. Br. Dent. J. 2017, 223, 183-189. [CrossRef]

2. AAPD. Guideline on restorative dentistry. Pediatr. Dent. 2016, 38, 250-262.

3. Da Mata, C.; McKenna, G.; Anweigi, L.; Hayes, M.; Cronin, M.; Woods, N.; O'Mahony, D.; Allen, P.F. An RCT of atraumatic restorative treatment for older adults: 5 year results. J. Dent. 2019, 83, 95-99. [CrossRef] [PubMed]

4. Baghdadi, Z.D.; Muhajarine, N. Effects of dental rehabilitation under general anesthesia on children's oral-health-related quality of life: Saudi Arabian parents' perspectives. Dent. J. 2015, 3, 1-13. [CrossRef]

5. Baghdadi, Z.D.; Jbara, S.; Muhajarine, N. Children's drawing as a projective measure to understand their experiences of dental treatment under general anesthesia. Children 2020, 7, 73. [CrossRef] [PubMed]

6. Moura, M.S.; Sousa, G.P.; Brito, M.H.S.F.; Silva, M.C.C.; Lima, M.D.M.; Moura, L.F.A.D.; Lima, C.C.B. Does low-cost GIC have the same survival rate as high-viscosity GIC in atraumatic restorative treatments? A RCT. Braz. Oral Res. 2020, 24, 125, Erratum in: Braz. Oral Res. 2020, 34, e125err. [CrossRef]

7. Alves, L.M.M.; Contreras, L.P.C.; Tribst, J.P.M.; de Melo, R.M.; Borges, A.L.S. Modified technique of porcelain laminate veneer in premolars with abfraction lesions: Three-dimensional finite element analysis (FEA). J. Health Sci. 2020, 22, 120-126. [CrossRef] 
8. Scholtanus, J.D.; Huysmans, M.C. Clinical failure of class-II restorations of a highly viscous glass- ionomer material over a 6-year period: A retrospective study. J. Dent. 2007, 35, 156-162. [CrossRef]

9. Caneppele, T.M.F.; de Souza, L.G.; Spinola, M.D.S.; de Oliveira, F.E.; de Oliveira, L.D.; Carvalho, C.A.T.; Bresciani, E. Bacterial levels and amount of endotoxins in carious dentin within reversible pulpitis scenarios. Clin. Oral Investig. 2020. [CrossRef]

10. Sarkar, N.K. Metal-matrix interface in reinforced glass ionomers. Dent. Mater. 1999, 15, 421-425. [CrossRef]

11. Kheur, M.; Kantharia, N.; Lakha, T.; Kheur, S.; Al-Haj Husain, N.; Özcan, M. Evaluation of mechanical and adhesion properties of glass ionomer cement incorporating nano-sized hydroxyapatite particles. Odontology 2020, 108, 66-73. [CrossRef]

12. Meneses, I.H.C.; Sampaio, G.A.M.; Carvalho, F.G.; Carlo, H.L.; Münchow, E.A.; Pithon, M.M.; Alves, P.M.; Lacerda-Santos, R. In vivo biocompatibility, mechanical, and antibacterial properties of cements modified with propolis in different concentrations. Eur. J. Dent. 2020, 14, 77-84. [CrossRef] [PubMed]

13. Zhang, F.; Xia, Y.; Xu, L.; Gu, N. Surface modification and microstructure of single-walled carbon nanotubes for dental resin-based composites. J. Biomed. Mater. Res. B Appl. Biomater. 2008, 86, 90-97. [CrossRef] [PubMed]

14. Borges, A.L.S.; Tribst, J.P.M.; Dal Piva, A.M.O.; Souza, A.C.O. In vitro evaluation of multi-walled carbon nanotube reinforced nanofibers composites for dental application. Int. J. Polym. Mater. 2020, 69, 1015-1022. [CrossRef]

15. Popov, A.M.; Lozovik, Y.E.; Fiorito, S.; Yahia, L. Biocompatibility and applications of carbon nanotubes in medical nanorobots. Int. J. Nanomed. 2007, 2, 361-372.

16. Kechagioglou, E.; Andriotis, P.; Papagerakis, S. Multiwalled carbon nanotubes for dental applications. In Odontogenesis; Humana Press: New York, NY, USA, 2019; pp. 121-128.

17. Sun, L.; Yan, Z.; Duan, Y.; Zhang, J.; Liu, B. Improvement of the mechanical, tribological and antibacterial properties of glass ionomer cements by fluorinated graphene. Dent. Mater. 2018, 34, 115-127. [CrossRef] [PubMed]

18. Pani, S.C.; Aljammaz, M.T.; Alrugi, A.M.; Aljumaah, A.M.; Alkahtani, Y.M.; AlKhuraif, A. Color stability of glass ionomer cement after reinforced with two different nanoparticles. Int. J. Dent. 2020, 31, 7808535. [CrossRef]

19. Tonelli, F.M.P.; Lacerda, S.M.S.N.; Silva, M.A.; Avila, E.S.; Ladeira, L.O.; Franca, L.R.; Resende, R.R. Gene delivery to Nile tilapia spermatogonial stem cells using carboxi-functionalized multiwall carbon nanotubes. RSC Adv. 2014, 4, 37985-37987. [CrossRef]

20. Chung, K.H. The properties of metal-reinforced glass ionomer materials. J. Oral Rehabil. 1993, 20, 79-87. [CrossRef]

21. Fareed, M.A.; Stamboulis, A. Nanoclay addition to a conventional glass ionomer cements: Influence on physical properties. Eur. J. Dent. 2014, 8, 456-463. [CrossRef]

22. Bresciani, E.; de Barata, T.J.; Fagundes, T.C.; Adachi, A.; Terrin, M.M.; Navarro, M.F. Compressive and diametral tensile strength of glass ionomer cements. J. Appl. Oral Sci. 2004, 12, 344-348. [CrossRef]

23. Rohr, N.; Fischer, J. Effect of aging and curing mode on the compressive and indirect tensile strength of resin composite cements. Head Face Med. 2017, 13, 22. [CrossRef]

24. Garoushi, S.; Vallittu, P.; Lassila, L. Hollow glass fibers in reinforcing glass ionomer cements. Dent. Mater. 2017, 33 , 86-93. [CrossRef]

25. Tribst, J.P.M.; Dal Piva, A.M.O.; de Jager, N.; Bottino, M.A.; de Kok, P.; Kleverlaan, C.J. Full-crown versus endocrown approach: A 3d-analysis of both restorations and the effect of ferrule and restoration material. J. Prosthodont. 2020, 28. [CrossRef]

26. Ausiello, P.P.; Ciaramella, S.; Lanzotti, A.; Ventre, M.; Borges, A.L.; Tribst, J.P.; Dal Piva, A.; Garcia-Godoy, F. Mechanical behavior of Class I cavities restored by different material combinations under loading and polymerization shrinkage stress. A 3D-FEA study. Am. J. Dent. 2019, 32, 55-60.

27. Ausiello, P.; Ciaramella, S.; De Benedictis, A.; Lanzotti, A.; Tribst, J.P.M.; Watts, D.C. The use of different adhesive filling material and mass combinations to restore class II cavities under loading and shrinkage effects: A 3D-FEA. Comput. Methods Biomech. Biomed. Eng. 2020, 22, 1-11.

28. Da Rocha, D.M.; Tribst, J.P.; Ausiello, P.; Piva, A.M.D.O.D.; Da Rocha, M.C.; Di Nicoló, R.; Borges, A.L.S. Effect of the restorative technique on load-bearing capacity, cusp deflection, and stress distribution of endodontically-treated premolars with MOD restoration. Restor. Dent. Endod. 2019, 44, e33. [CrossRef]

29. Baghdadi, I.; Zaazou, A.; Tarboush, B.A.; Zakhour, M.; Özcan, M.; Salameh, Z. Physiochemical properties of a bioceramic-based root canal sealer reinforced with multi-walled carbon nanotubes, titanium carbide and boron nitride biomaterials. J. Mech. Behav. Biomed. Mater. 2020, 110, 103892. [CrossRef]

30. Pratap, B.; Gupta, R.K.; Bhardwaj, B.; Nag, M. Evaluation of compressive strength and void content of resin based dental composites. Mater. Today 2020. [CrossRef]

31. Sidhu, S.K.; Nicholson, J.W. A Review of Glass-Ionomer Cements for Clinical Dentistry. J. Funct. Biomater. 2016, 7, 16. [CrossRef]

32. Cascos-Sanchez, R.; Molinero-Mourelle, P.; Ortega, R.; Agustin-Panadero, R.; Del Rio Highsmith, J.; Gomez-Polo, M. Comparative in vitro study of the bond strength of composite to carbon fiber versus ceramic to cobalt-chromium alloys frameworks for fixed dental prostheses. Materials 2020, 13, 3173. [CrossRef]

33. Tzounis, L.; Petousis, M.; Grammatikos, S.; Vidakis, N. 3D Printed thermoelectric polyurethane/multiwalled carbon nanotube nanocomposites: A novel approach towards the fabrication of flexible and stretchable organic thermoelectrics. Materials 2020, 13, 2879. [CrossRef]

34. Chieruzzi, M.; Pagano, S.; Lombardo, G.; Marinucci, L.; Kenny, J.M.; Torre, L.; Cianetti, S. Effect of nanohydroxyapatite, antibiotic, and mucosal defensive agent on the mechanical and thermal properties of glass ionomer cements for special needs patients. $J$. Mater. Res. 2018, 33, 638-649. [CrossRef] 
35. Yeo, H.W.; Loo, M.Y.; Alkhabaz, M.; Li, K.C.; Choi, J.J.E.; Barazanchi, A. Bulk-fill direct restorative materials: An in vitro assessment of their physio-mechanical properties. Oral 2021, 1, 8. [CrossRef]

36. Ausiello, P.; Dal Piva, A.M.d.O.; Borges, A.L.S.; Lanzotti, A.; Zamparini, F.; Epifania, E.; Mendes Tribst, J.P. Effect of shrinking and no shrinking dentine and enamel replacing materials in posterior restoration: A 3D-FEA study. Appl. Sci. 2021, 11, 2215. [CrossRef] 